\title{
FEA Modelling of the Combined Hard Turning- Rolling Process Used at Bearing Rings
}

\author{
Gures Dogan ${ }^{1}$, Ilhan Mehmet $^{1}$, Dragoș Florin Chitariu ${ }^{2, *}$, Cătălin Gabriel Dumitraș ${ }^{2}$ and \\ Vasile Ionuț Crîșmaru ${ }^{1}$ \\ ${ }^{1}$ Technical University GHEORGHE ASACHI Iași, Faculty of Machine Manufacturing and Industrial \\ Management, 700050 B-dulProf.Mangeron No.59A, Romania \\ ${ }^{2}$ Technical University GHEORGHE ASACHI Iași, Machine Tools and Cutting Tools Department, \\ 700050 B-dul Prof Mangeron 39A, Iaşi, Romania
}

\begin{abstract}
In general, the production of bearings is a very large series production, which is why in production the technological lines are designed to process a single size of bearings. Changing the production line for different types of bearings is expensive and time consuming, especially where grinding and honing processes are required. An alternative to these abrasive processes is hard turning. The literature indicates that due to highprecision machines, the accuracy of hard-turned parts is comparable to grinding processes. It is also indicated that the integrity of the surface and the topography of the surface together with the residual induced stresses are parameters of interest and that influence the performance of the bearings. So one method of increasing the durability of the bearings is to ensure a low roughness of the elements and high residual induced stresses. Deep rolling is considered as an alternative to honing and rectification processes. Rolling can induce higher surface stresses in the material compared to honing and grinding. The present paper proposes a combined cutting tool made of a hard turning head and a rolling cutting tool for machining bearing rings. A simulation of this combined process is performed with the help of the finite element and thus the internal stress field, the temperature fieldand the topography of the processed surface aredetermined.
\end{abstract}

\section{Introduction}

The operating conditions of the bearings impose rigorous geometric precision conditions, although they are seemingly simple machine parts, the internal geometry is a complex one. For proper functioning and high durability are of vital interest determination of stresses and deflections [1]. Residual stress is the stress that remains within a material of the bearing components in the absence of external loading or thermal gradients. Bearing durability can be increased by inducing compressive residual stresses and obtaining low surface roughness. The state of residual stresses is influenced by heat treatments, manufacturing methods especially for bearing rings $[2,3,4,5]$.

Corresponding author: chitariudragos@gmail.com 
The manufacturing processes of bearing rings are complex and require a succession of stages (production route) that takes place in different sectors of a factory, also the manufacturing process is inflexible involving many adjustments of machine tools usually specialized, when changing between different types of manufacturing batches. In order to increase the flexibility of the process and to reduce the manufacture process steps various researches and methodologies have been identified regarding the possibilities of reduction of the production route, mainly in the machining sector such as Trenpro process [6].

The process of hard turning is used for finishing of parts (roller rings) with high accuracy of $\mathrm{f}$ material with hardness over 45-47 HRC, with cutting materials such as CBN, ceramics or coated carbide. In the past these parts could only be machinined by grinding [4].

In order to improve the mechanical characteristics of the roller rings different mechanical treatments as roller, multi roller or ball burnishing can be applied to the active surfaces [9]. These processes have the advantage of making a superficial plastic deformation without chip detachment, under the action of pressing and moving on their surface one or more tools without cutting edges, between the "tool" and the machined surfaces of the roller bearing, there is a relative rotational or translational movement. The working principle is based on the transfer of the force applied on a roller / sphere to the surface on a certain path. During the rotation action, the contact area is so small that the hertz type pressure appears on the surface of the deformed material.

Various manufactures of rolling/ deep rolling/ burnishing tool offer informations on the advantages of the effects of roller burnishing operation on the durability - increase in resistance to fatigue failure, increase in Brinell Hardness on surface, surface roughness, of the parts machined $[10,11]$ (fig.1).

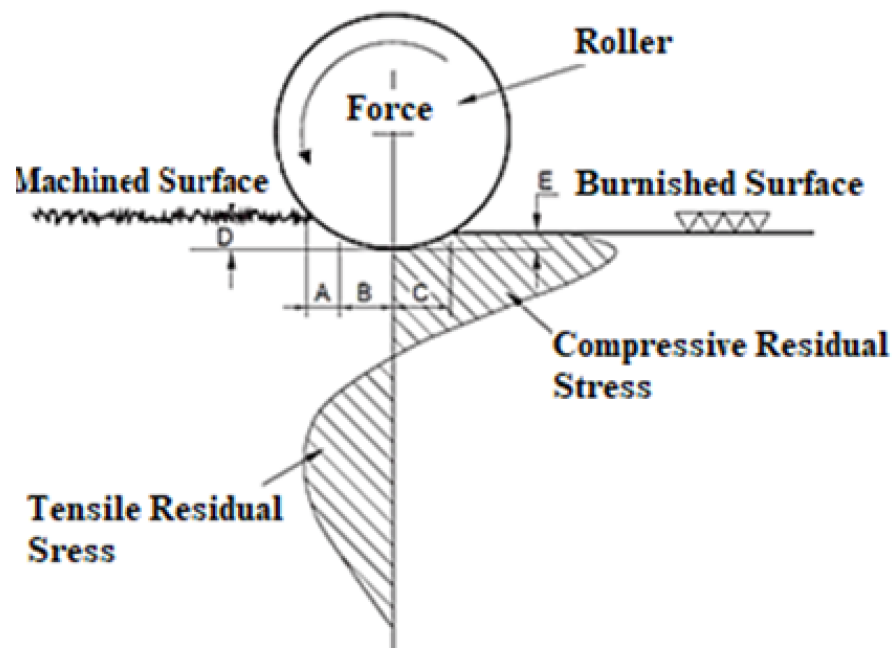

Fig. 1. Principle of roller burnishing process by YAMATO tool manufacturer [10]

Maiß O, Denkena B., Grove T. proposed new reduced process routes for manufacturing roller bearing by replacing the highly costly grinding process with hard turning or a hybrid process of hard turning and deep rolling performed simultaneous on the same CNC lathe [7] (fig.2). The proposed process represent an development of the turning and deep cold rolling process proposed by Axinte and Gindy [8]. 


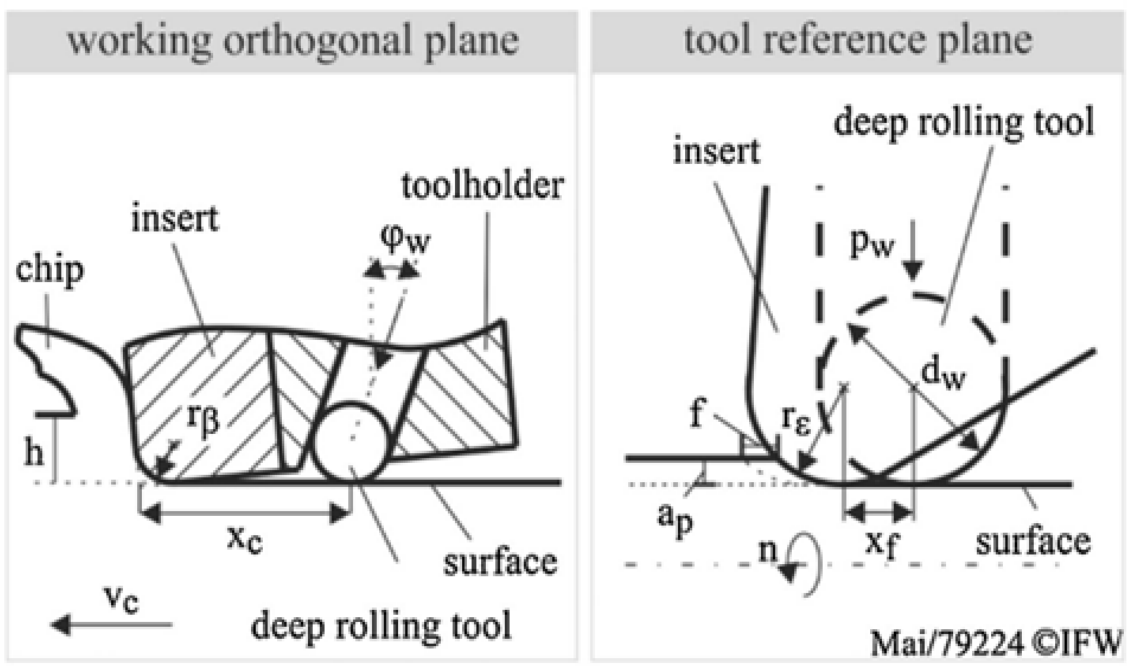

Fig.2. View of the hybrid hard turn-rolling process proposed [7]

A similar combined process has been experimented by Mezlini and collaborators (fig.3) by associating a carbide cutting tool and a ball burnishing tool on a lathe in order to improve surface roughness and reduce technological time [9].

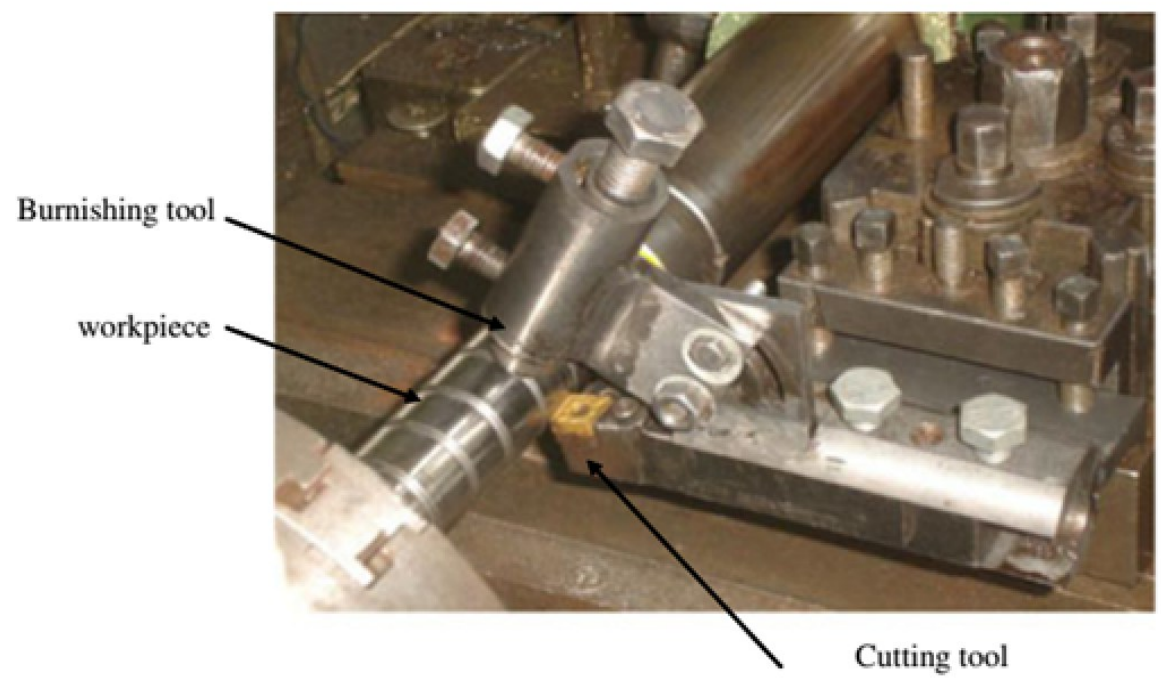

Fig.3. View of combined tools used [9]

Based on the data described above one propose a new combined hard turning-rolling process used finishing operation of the inner races of the bearing. This process is described in the following. The finite element analysis will be carried out for this type of process in order to obtain data of the residual stress in the inner rig of a bearing.

\section{Experimental Design}

In order to determine the residual stress in the inner race of a bearing one take into account the following data for the experiment. 
We consider the data for the inner race presented in fig.4.
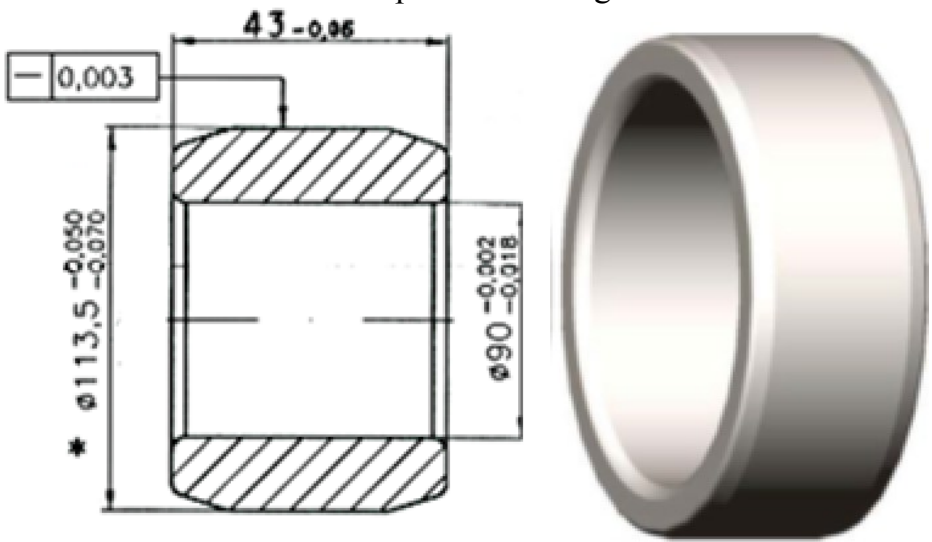

Fig.4. Presentation of the inner race geometry

The process will be carried out on a CNC machine tool type ECOCA MT312 (fig.5).

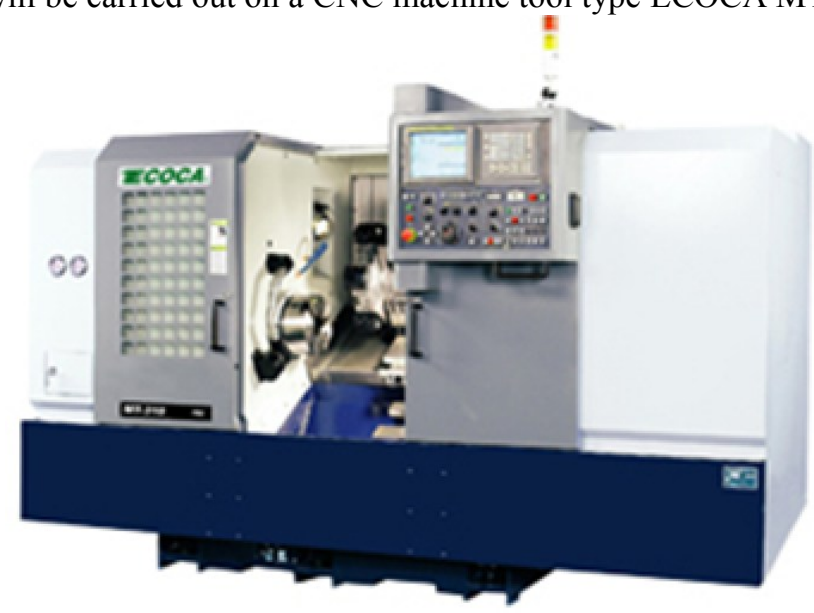

Fig.5. Presentation of the $\mathrm{CNC}$ machine tool

Both process, hard turning and rolling, will be carried out on the same machine tool. The data for the cutting tool are the following: turning tool type is SVVBN2525M16, the insert type isVBGW160408 $\mathrm{R}=0.8$. The turning tool is produce by KYOCERA. The insert is presented in fig.6.
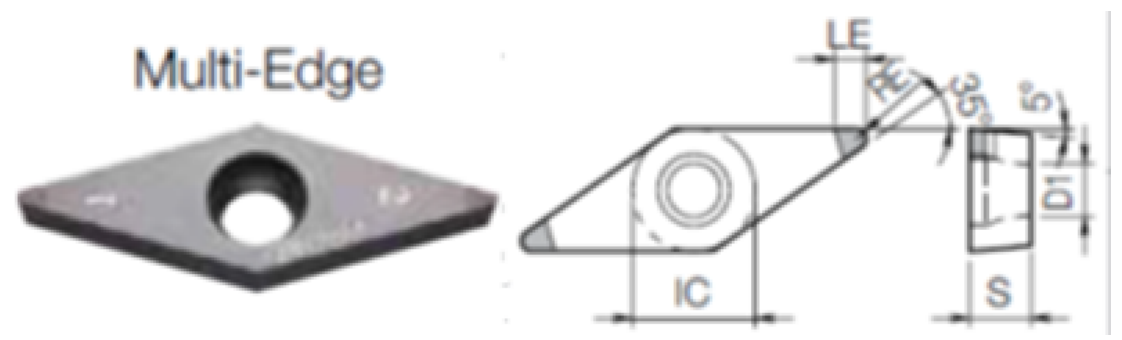

Fig.6. The insert geometry

The data for the worked material are given in the following tables. 
Table 1. Chemical composition

\begin{tabular}{|c|c|c|c|c|c|c|c|c|c|}
\hline \multirow{2}{*}{ Steel type } & \multicolumn{7}{|c|}{ Chemical composition, \% } \\
\cline { 2 - 10 } & $\mathbf{C}$ & $\mathbf{M n}$ & $\mathbf{S i}$ & $\mathbf{C r}$ & $\begin{array}{c}\text { Mo } \\
\text { max. }\end{array}$ & $\begin{array}{c}\text { S } \\
\text { max. }\end{array}$ & $\begin{array}{c}\text { P } \\
\text { max. }\end{array}$ & $\begin{array}{c}\text { Ni } \\
\text { max. }\end{array}$ & $\begin{array}{c}\text { Cu } \\
\text { max. }\end{array}$ \\
\hline $\mathbf{1 0 0 C r M n S i 6 - 4}$ & $0.93 \div 1$. & $1 . \div 1.2$ & $0.45 \div 0.7$ & $1.4 \div 1.65$ & 0.1 & 0.015 & 0.025 & 0.25 & 0.25 \\
\hline
\end{tabular}

Table 2. Properties of the bearing steel

\begin{tabular}{|c|c|c|c|c|c|}
\hline $\begin{array}{c}\text { Hardness } \\
\text { (HRC) }\end{array}$ & $\begin{array}{c}\mathbf{R m}(\mathbf{M p a}) \\
\mathbf{R m}\left(\mathbf{N} / \mathbf{m m}^{2}\right)\end{array}$ & $\begin{array}{c}\mathbf{R p}_{\mathbf{0 . 2}}(\mathbf{M p a}) \\
\mathbf{R} \mathbf{N}\left(\mathbf{N} \mathbf{m m}^{2}\right)\end{array}$ & $\mathbf{A}_{\mathbf{5}}(\mathbf{\%})$ & $\mathbf{Z}(\mathbf{\%})$ & Equivalent \\
\hline $61 \div 64$ & 2300 & 1700 & 2 & 2 & $\begin{array}{c}837 \mathrm{~B} \\
(\text { OVAKO) }\end{array}$ \\
\hline
\end{tabular}

The rolling tool is presented in fig. 7. This tool is manufactured by ECOROLL.

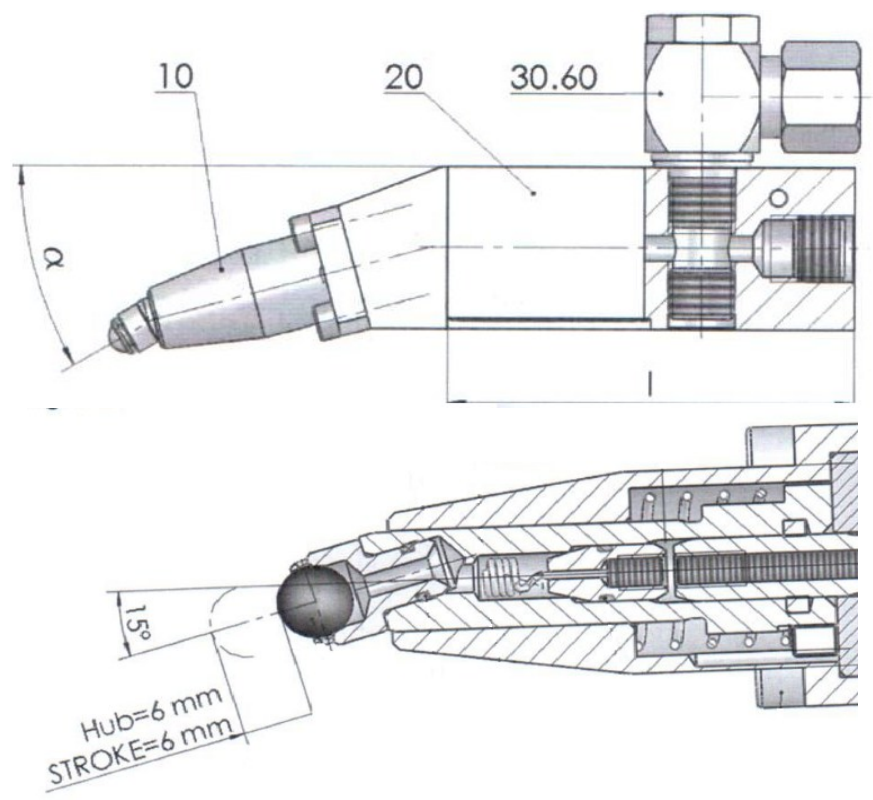

Fig. 7. Rolling tool ECOROLL HG6-9R30-SLK

This are the starting data used in the finite element analysis.

\section{Finite Element Model}

In order to obtain the results regarding the residual stress in the processed workpiece one use finite element analysis. The software used is ANSYS release 2020. This FEA software has the possibility to model the cutting process with chip removal. This can be done due to special type of finite element which can be uncoupled when the tangential stress is bigger than the half value of the normal stress, thus we can simulate the detachment of the chip. In 
fig. 8 one present the finite element model. We use 59000 elements. One consider that the cutting tool is non-deformable.

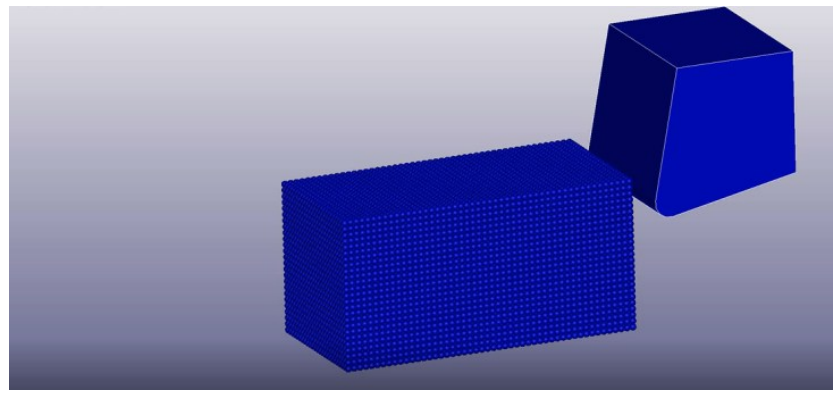

Fig. 8. Finite Element Model

The second finite element model consider the bearing as a whole. This model intend to determine the tension inside the bearing considering the initial state of internal tension. There were use 234000 finite elements type Solid186.

\section{Results}

In the following one present the results.

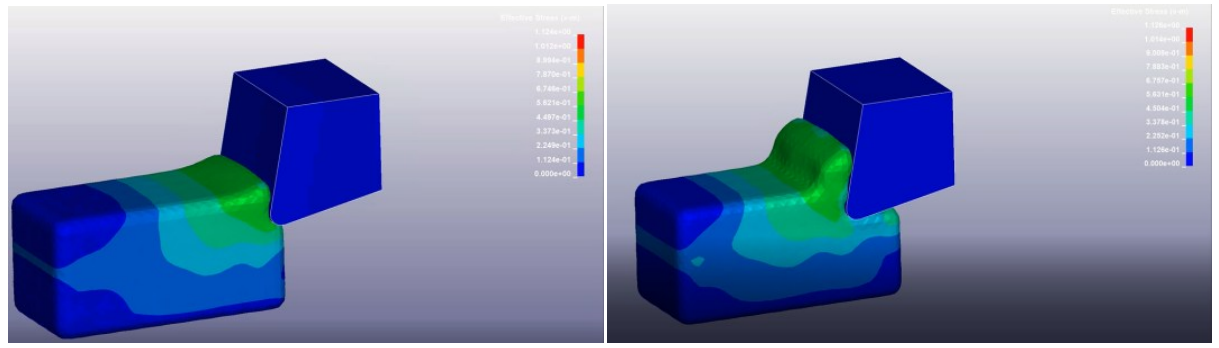

a). b).

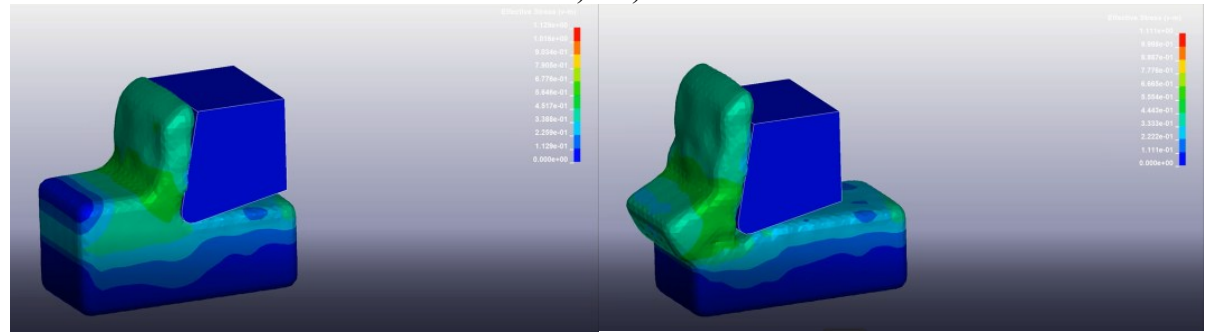

c).

d)

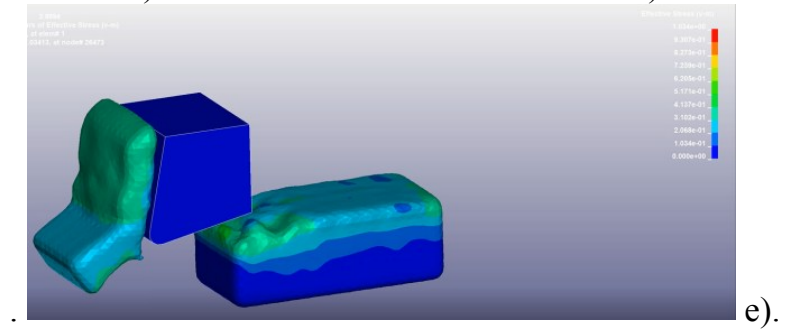

Fig.9. Resulting stress Von Mises at various periods of time:a). $T=0.3 \mathrm{~s}, \mathrm{~b}$ ). $\mathrm{T}=0.7 \mathrm{~s}, \mathrm{c}) . \mathrm{T}=1.24 \mathrm{~s}, \mathrm{~d}$ ). $\mathrm{T}=1.8 \mathrm{~s}, \mathrm{e}) . \mathrm{T}=2.96 \mathrm{~s}$ 
In fig. 9 we present a cutting model for the inner race of the bearing. During this process one obtain an internal remnant stress. The process of obtaining the inner race will continue with the rolling operation. This two operation, the cutting operation and rolling operation will be carried out on the same CNC machine tool.

Also, one simulate the temperature during the cutting operation. In fig. 10 one present the temperature at the beginning and at the end of the process. This temperature will also contribute to the internal stress.

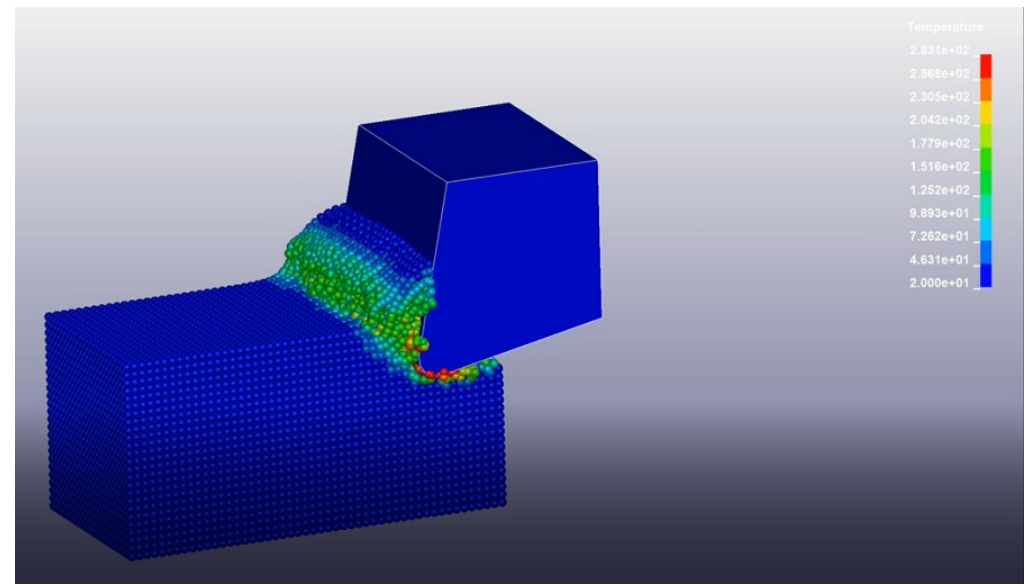

a).

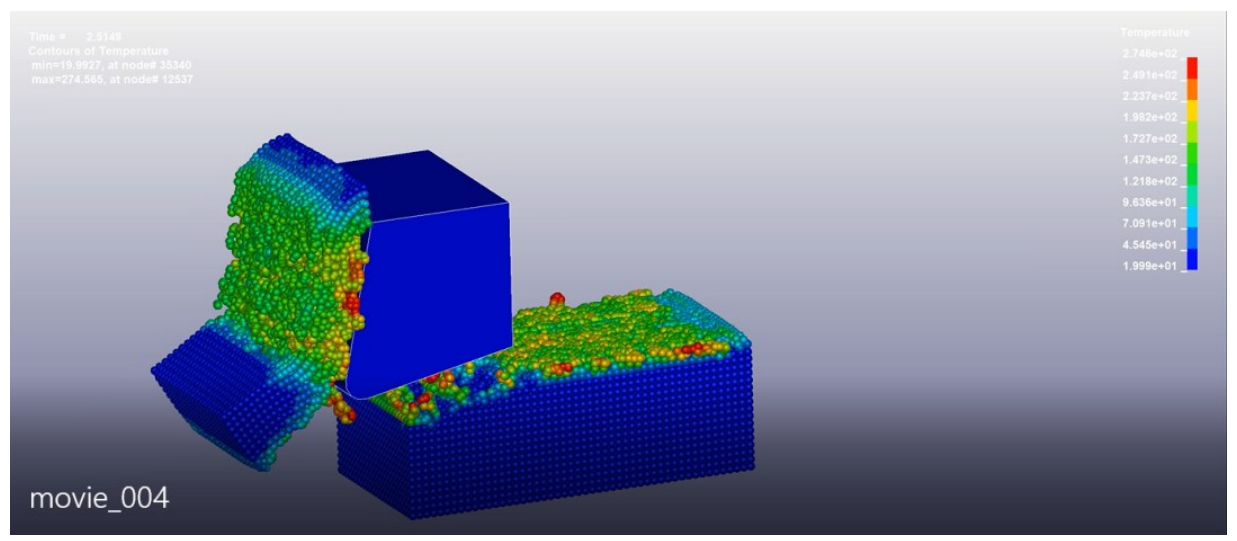

b).

Fig.10. Temperature at various periods of time a). $T=0,8 \mathrm{~s}, \mathrm{~b}) . \mathrm{T}=2.96 \mathrm{~s}$

In following figures one present the stress in the inner races during the usage of the bearing. On take into account the residual stress in the race.

In fig. 11 one present the 2D model and in fig 12 the $3 \mathrm{D}$ model. 


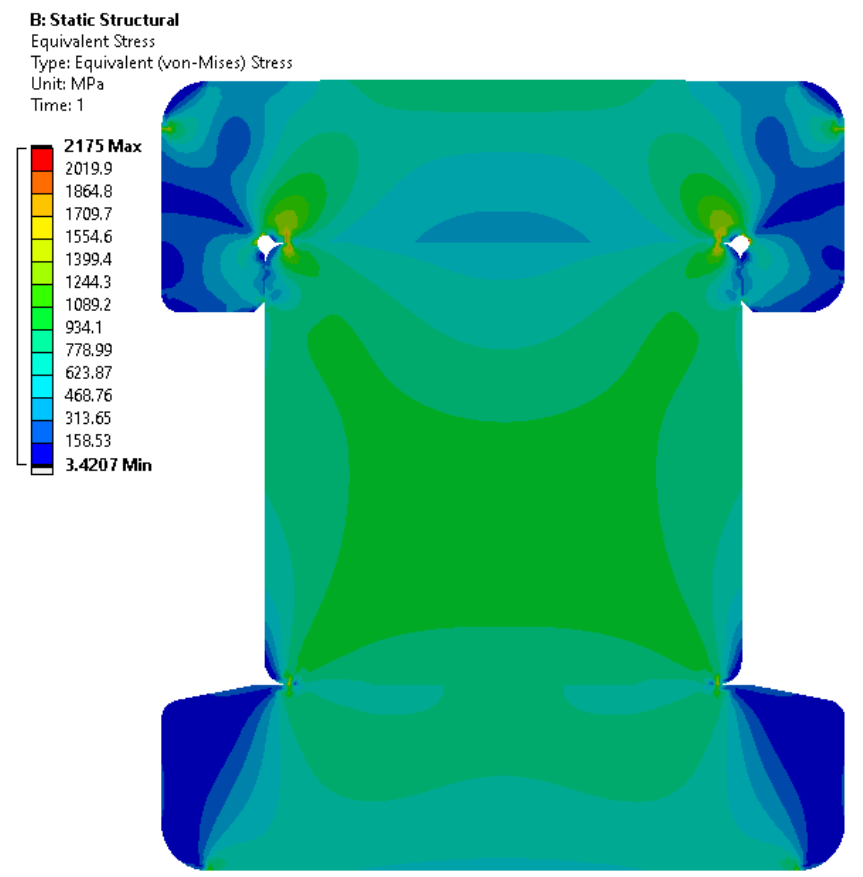

Fig.11. Stress in the bearing - 2D model

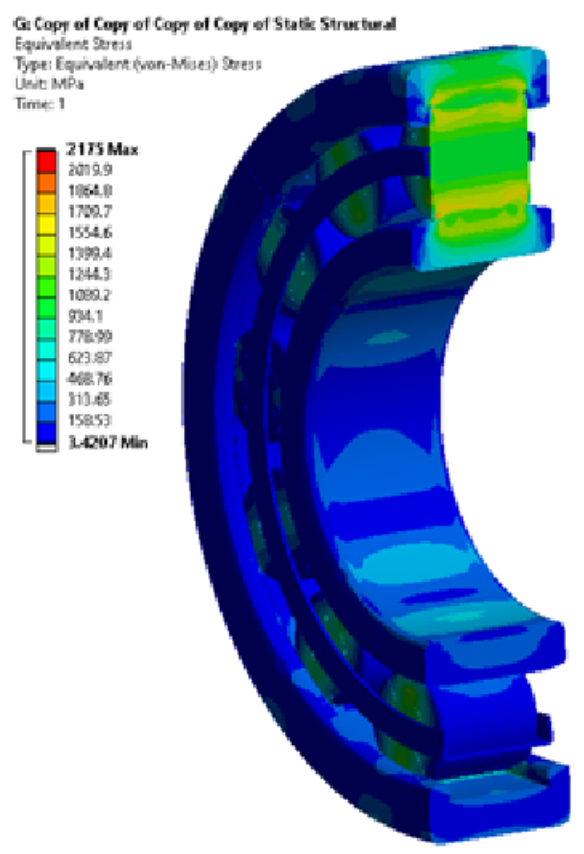

Fig.12. Stress in the bearing - 3D model

In order to certify the finite element model we develop an experiment which consider the bearing at maximum load during 24 hours. The obtained measuring data are presented in fig. 13 and 14. 

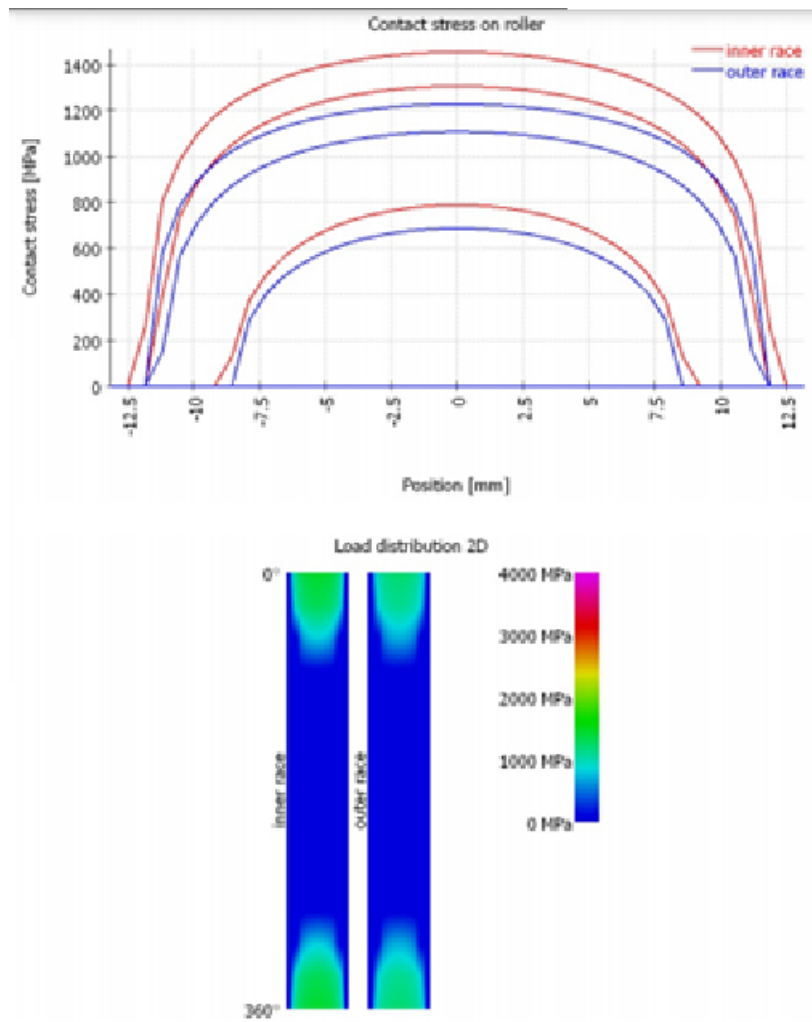

$+600 \mathrm{MFa}$
$3000 \mathrm{MPa}$
$2000 \mathrm{MFa}$
$1000 \mathrm{MPa}$
$0 \mathrm{MFa}$

Fig.13. Stress in the bearing on inner and outer race

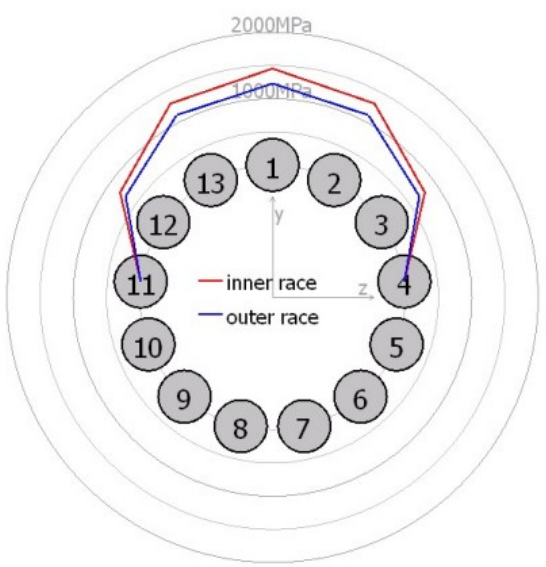

Fig.14. The distribution of the stress in the loaded bearing on inner and outer race

The data presented in fig. 13 and 14 represent the contact stress measured in the inner and outer race. In fig. 13 one present the stress measured in radial section along the inner race edge. In fig. 14 we present the distribution of the contact stress in the bearing plane section. 


\section{Conclusions}

Based on the results of the finite element analysis one can conclude:

- The residual stress due to cutting process is minimum and the functionality of the bearing will not be influenced.

- The value of the equivalent stress on the inner race in the finite element analysis is between 1399.4 and $1554.6 \mathrm{MPa}$

- The maximum measured value on the inner race of the bearing during the experiment is $1400 \mathrm{MPa}$

- The maximum error obtain during the simulation is considered to be $11 \%$ which can be considered good and the finite element analysis can be validated.

- The temperature in cutting process have little influence in bearing functionality. The level of the temperature in cutting process is maximum $240^{\circ} \mathrm{C}$

- The rolling process is still under revise. This process have more influence on processed surface roughness than residual stress.

The FEA results will be compared with the experimental results. The experiment is ongoing.

\section{References}

1. H. Tedric, Rolling bearing analysis 5th ed. (Boca Raton, FL, CRC, 2007)

2. S.S. Cretu, M.I. Benchea, O.S. Cretu, IMECE 2007, Compressive Residual Stresses Effect on Fatigue Life of Rolling Bearings (Washington, USA, 2007)

3. B. Denkena, T. Grove, O. Maiss, Procedia CIRP, 45 (2016)

4. B. Denkena, T. Grove, O. Maiss, Prod. Eng. Res. Devel., 9, 3 (2015)

5. F., Pape, T. Neubauer, O. Maißetal., Tribol. Lett., 65, 70 (2017)

6. J.Cappel,M. Weinberg, R. Flender, Steel Grips, 2 (1990)

7. O.Maiß, B.Denkena, T.Grove, Journal of Materials Processing Technology, 230 (2016)

8. D. A. Axinte, N. Gindy, Journal of Engineering Manufacture, 218, 7 (2004)

9. S. Mezlini et. al, Lubrication Science, 26 (2014)

10. https://www.yamatoroll.eu/art-of-roller-burnishing-yamato/, [Accessed 12.08.2020]

11. https://www.ecoroll.de/en/processes/deep-rolling.html, [Accessed 18.08.2020] 